\title{
PATTERN OF SEXUALLY TRANSMITTED DISEASES (STDs) AMONG PATIENTS ATTENDING OUT PATIENT DEPARTMENT OF DERMATOLOGY OF DHAKA MEDICAL COLLEGE HOSPITAL, DHAKA, BANGLADESH
}

\author{
ALI CM ${ }^{1}$, SIKDAR TK $^{2}$, SULTANA N $^{3}$, AHMED N $^{2}$, HAQUE AKMR $^{2}$, KAMAL SMB $^{2}$, PARVEZ MZ $^{2}$, \\ HAQUE $\mathrm{ME}^{2}$
}

\begin{abstract}
:
The study was conducted among 568 patients of STDs out of 58560 male and female patients in the OPD of Dermatology Department of Dhaka Medical College Hospital (DMCH) during the period of March 2009 to February 2010 irrespective of sex and age >15 years with a view to assess the prevalence of sexually transmitted diseases. In this study prevalence of STDs such as gonorrhea, syphilis, non gonococcal urethritis, chancroid, genital herpes and genital warts were $29.58 \%, 12.68 \%, 41.58 \%, 4.93 \%, 8.45 \%$ and $2.82 \%$ respectively; male and female ratio were 3.73:1. The highest prevalence rate was found in age group of 25-34 years (42.25\%). According to educational status of the respondents, $33.80 \%$ were up to secondary level and only $2.82 \%$ were master degree holder. Among occupation $36.62 \%$ were in service, and $15.49 \%$ were students. According to socioeconomic status $40.14 \%$ were poor and only $9.86 \%$ were from upper middle class.
\end{abstract}

Key words: Sexually transmitted diseases, prevalence.

J Dhaka Med. Coll. 2010; 19(1) : 7-10.

\section{Introduction:}

Sexually transmitted diseases (STDs) affect men and women of all backgrounds and economic levels. CDC estimates that 19 million new infections occur each year, almost half of them among young people ages 15 to $24 .^{1}$ Common STDs are Acquired Immune Deficiency Syndrome (AIDS), Chancroid, Genital HPV Infection, Gonorrhea, Syphilis, Trichomoniasis and Viral Hepatitis. ${ }^{2}$ Many of these STDs initially cause no symptoms, especially in women. When symptoms develop, they may be confused with those of other diseases that are not transmitted through sexual contact. STDs can still be transmitted from person to person even if they do not show symptoms. Furthermore, health problems caused by STDs tend to be more severe for women than for men. Acquired immune deficiency syndrome (AIDS) was first reported in the United States in 1981.

AIDS is caused by the human immunodeficiency virus (HIV), a virus that destroys the body's ability to fight against infection. People who have AIDS are very susceptible to many life-threatening diseases, called opportunistic infections, and to certain forms of cancer. Transmission of the virus primarily occurs during unprotected sexual activity and by sharing needles used to inject intravenous drugs. 1,2,3,6 Chancroid is a bacterial infection caused by Haemophilus ducreyi, which is spread by sexual contact and results in genital ulcers. The infection begins with the appearance of painful open sores on the genitals, sometimes accompanied by

1. Associate Professor and Head, Department of Dermatology, Dhaka Medical College, Dhaka

2. Assistant Professor, Department of Dermatology, Dhaka Medical College, Dhaka

3. Assistant Professor, Department of Obstetrics \& Gynaecology, Dhaka Medical College, Dhaka

Correspondence : Dr. Chowdhury Mohammad Ali. 
swollen, tender lymph nodes in the groin. These symptoms occur within a week after exposure. Symptoms in women are often less noticeable and may be limited to painful urination or defecation, painful intercourse, rectal bleeding, or vaginal discharge. Chancroid lesions may be difficult to distinguish from ulcers caused by genital herpes or syphilis. A physician must therefore diagnose the infection by excluding other diseases with similar symptoms. Chancroid is one of the genital ulcer diseases that may be associated with an increased risk of transmission of the human immunodeficiency virus (HIV), the cause of AIDS. ${ }^{2,3}$ Chlamydial infection is a common STD caused by the bacterium Chlamydia trachomatis. Chlamydia is the most frequently reported bacterial STD in the United States. Chlamydia can be transmitted during vaginal, oral, or anal sexual contact with an infected partner. ${ }^{1,3}$ Genital herpes is a contagious viral infection caused by the herpes simplex virus (HSV). There are two types of HSV: herpes simplex virus type 1 (HSV-1) and type 2 (HSV-2). Both can cause genital herpes, although most genital herpes is caused by HSV2. HSV-1 most commonly causes sores on the lips, but it can cause genital infections through oral-genital or genital-genital contact. HSV-2 symptoms typically appear as one or more blisters on or around the genitals or rectum. The virus remains in certain nerve cells of the body for life, causing periodic symptoms in some people. ${ }^{1,2,4}$ Human papillomavirus (HPV) is the most common STD. There are more than 40 HPV types that can infect the genital areas of males and females. These HPV types can also infect the mouth and throat. ${ }^{3}$ Low-risk types of HPV cause genital warts, the most recognizable sign of genital HPV infection. Other high-risk types of HPV cause cervical cancer and other genital cancers. Most people with HPV do not develop symptoms or health problems. ${ }^{4}$ Gonorrhea is caused by Neisseria gonorrhoeae, a bacterium that can grow and multiply easily in the warm, moist areas of the reproductive tract. The most common symptoms of infection are a discharge from the vagina or penis and painful or difficult urination. The most common and serious complications occur in women and, as with chlamydial infection, these complications include pelvic inflammatory disease (PID), ectopic pregnancy, and infertility. ${ }^{1,3}$ Syphilis is caused by the bacterium Treponema pallidum. Syphilis is passed from person to person through direct contact with syphilis sores. The first symptoms of syphilis infection may go undetected because they are very mild and disappear spontaneously. The initial symptom is a chancre, it is usually a painless open sore that most often appears on the penis or around or in the vagina. It can also occur near the mouth, anus, or on the hands. Transmission of the organism occurs during vaginal, anal, or oral sex. Pregnant women with the disease can pass it to the babies they are carrying. ${ }^{1,3,7}$ Trichomoniasis is caused by the single-celled protozoan parasite, Trichomonas vaginalis. It is the most common curable STD in young, sexually active women, and it affects men as well although symptoms are most common in women. The vagina is the most common site of infection in women, and the urethra is the most common site of infection in men. ${ }^{1,8}$

\section{Materials and Methods:}

It was a cross sectional study conducted in Dermatology outpatient department (OPD) of Dhaka Medical College Hospital (DMCH) during the period of March 2009 to February 2010. The objective of the study was to observe prevalence of STDs patients out of total male and female patients attending Dermatology OPD. A total of 58560 male and female patients were attended in OPD of Dermatology Department except paediatric patients from which 568 patients were diagnosed as STDs. Data were collected by using a predesigned questionnaire. A detailed history of the patient covering age, sex, education, occupation and socioeconomic status were taken. Each STD patient of 568 were examined thoroughly and confirmed by serological and also microscopic examination which was applicable.

\section{Results:}

All findings of this study have been summarized in the following tables: 
Table I

Distribution of respondents by sex groups

\begin{tabular}{lccc}
\hline STDs & Male (\%) & Female (\%) & No. of patients (\%) \\
\hline Syphilis & $64(11.26)$ & $8(1.42)$ & $72(12.68)$ \\
Gonorrhea & $136(23.94)$ & $32(5.64)$ & $168(29.58)$ \\
Chancroid & $28(4.93)$ & $0(0)$ & $28(4.93)$ \\
Genital Herpes & $32(5.64)$ & $16(2.82)$ & $48(8.45)$ \\
Genital Warts & $12(2.11)$ & $4(0.71)$ & $16(2.82)$ \\
Non gonococcal urethritis(NGU) & $176(30.99)$ & $60(10.55)$ & $236(41.54)$ \\
\hline Total $(\mathrm{n}=568)$ & $448(78.87)$ & $120(21.13)$ & $568(100)$ \\
\hline
\end{tabular}

Table II

Distribution of respondents by age group

\begin{tabular}{lccccccc}
\hline Years & Syphilis & Gonorrhea & Chancroid & $\begin{array}{c}\text { Genital } \\
\text { Herpes }\end{array}$ & $\begin{array}{c}\text { Genital } \\
\text { Warts }\end{array}$ & $\begin{array}{c}\text { Non gonococcal } \\
\text { urethritis (NGU) }\end{array}$ & $\begin{array}{c}\text { Total } \\
(\mathrm{n}=568) \%\end{array}$ \\
\hline $15-24$ & 16 & 48 & 0 & 0 & 0 & 44 & $108(19.14)$ \\
$25-34$ & 32 & 72 & 12 & 32 & 4 & 88 & $240(42.25)$ \\
$35-44$ & 16 & 36 & 8 & 8 & 8 & 56 & $132(23.24)$ \\
$45-54$ & 8 & 8 & 4 & 4 & 4 & 28 & $60(10.56)$ \\
55 and above & 0 & 4 & 4 & 0 & 0 & 20 & $28(4.93)$ \\
\hline Total & $72(12.68)$ & $168(29.58)$ & $28(4.92)$ & $48(8,45)$ & $16(2.82)$ & $236(41.55)$ & $568(100)$ \\
\hline
\end{tabular}

Table III

Distribution of respondents by educational status

\begin{tabular}{lcc}
\hline Education & Cases & $(\mathrm{n}=568) \%$ \\
\hline Illiterate & 44 & 7.75 \\
Primary & 156 & 27.46 \\
Secondary & 192 & 33.80 \\
HSC & 68 & 11.97 \\
Graduate & 92 & 16.20 \\
Masters & 12 & 2.82 \\
\hline Total & 568 & 100 \\
\hline
\end{tabular}

Table IV

Distribution of respondents by occupation

\begin{tabular}{lcc}
\hline Occupation & Cases & $(\mathrm{n}==568) \%$ \\
\hline Service & 208 & 36.62 \\
Business & 100 & 17.61 \\
Agriculture & 84 & 14.79 \\
Student & 88 & 15.49 \\
House wife & 52 & 9.15 \\
Others & 36 & 6.34 \\
\hline Total & 568 & 100 \\
\hline
\end{tabular}

Table-V

Distribution of respondents by socioeconomic status

\begin{tabular}{lcc}
\hline Socioeconomic status & Cases & $\%$ \\
\hline Poor & 228 & 40.14 \\
Lower middle class & 184 & 32.39 \\
Middle class & 100 & 17.61 \\
Upper middle class & 56 & 9.86 \\
\hline Total & 568 & 100 \\
\hline
\end{tabular}

\section{Discussion:}

In this study, a total number of 568 Sexually Transmitted Diseases (STDs) patients out of 58560 Out Patient Department (OPD) patients of different age groups( $15->55$ years) and sexes associated with different STDs were studied in Dhaka Medical College Hospital (DMCH) of Dermatology Department during the period of March 2009 to February 2010. The STDs patients who were diagnosed by clinical, serological and microscopic examinations 
respectively depend upon different types of STDs. The prevalence rate of STDs in this study was $0.97 \%$. The male and female ratio was 3.73:1. In table-I, among the respondents, gonorrhea were $29.58 \%, 12.68 \%$ were syphilis, non gonococcal urethritis(NGU) were $41.58 \%$ and chancroid ,genital herpes, genital warts were $4.93 \%, 8.45 \%$ and $2.82 \%$ respectively. Among the respondents $78.87 \%$ were male and $21.13 \%$ were female. A study conducted by Dermatology Department of Dhaka Medical College Hospital from 1999 to 2004 in which the prevalence of STDs (Syphilis, Gonorrhea, Chancroid, Genitalherpes, NGU, Genital Warts and LGV) were $16.3 \%, 32.5 \%, 6.5 \%, 3.0 \%$, $41.4 \%, 3.0 \%$, and $0.1 \%$ respectively. In this current study, the highest prevalence rate was $42.25 \%$ on age group of $25-34$ years. Among educational status (Table-III) showed $33.80 \%$ respondents were up to secondary level and the next majority was $27.46 \%$ up to the primary level and only $2.82 \%$ were master degree holder. The highest rate among occupation $36.62 \%$ were in service, $17.61 \%$ were businessman, $14.79 \%$ agriculturist, $15.49 \%$ students and $9.15 \%$ were housewives (TableIV). The socioeconomic status (Table-V) also showed $40.14 \%$ were poor, $32.39 \%$ were lower middle class and only $9.86 \%$ were upper middle class. In this current study, we had found prevalence of STDs in a tertiary teaching hospital for one year period ( March 2009 to February 2010) and also found different pattern of STDs who were attended at Out Patient Department of Dermatology department of Dhaka Medical College Hospital.

\section{Conclusion:}

The study was done to assess the prevalence of STDs attending in OPD of government hospital like $\mathrm{DMCH}$ and we had found the highest incidence among all STDs was NGU which was $41.58 \%$, among age group of 25-34 years the highest incidence was $42.25 \%$. The highest incidence among educational and socioeconomic status were $33.8 \%$ in secondary level and $40.41 \%$ in poor class respectively. A large scale study may be done with long duration of study period which may give the actual scenerio of STDs.

\section{References:}

1. CDC. Sexually Transmitted Diseases in the United States. National Surveillance Data for Chlamydia, Gonorrhea, and Syphilis. Atlanta: U.S. Department of Health and Human Services; 2009. [cited 2010 March 18]. Available from: http://www.cdc.gov/ std/stats08/trends.htm

2. CDC. Trends in Reportable Sexually Transmitted Diseases in the United States. Atlanta: U.S. Department of Health and Human Services; 2008. [cited 2008 Dec 2]. Available from: http:// www.cdc.gov/std/stats06/trends2006.htm.

3. Kamb ML, Fishbein M, Douglas JM, et al. Efficacy of risk reduction counseling to prevent human immunodeficiency virus and sexually transmitted diseases: a randomized control trial. JAMA. 1998; 280: 1161-67.

4. CDC. Genital HPV Infection. Atlanta: U.S. Department of Health and Human Services.2009, [cited 2010 March 19]. Available from: http: / /www.cdc.gov/std/HPV/STDFactHPV.htm.

5. Gortlieb SL, Douglas JM, Froster M, et al. Incidence of herpes simplex virus type 2 infection in 5 sexually transmitted disease clinics and the effect of HIV/STD risk reduction counseling. J Infect Dis. 2004; 190: 1059-67.

6. Jansean RS, Holtgrave DR, Valdiserri RO, Sheperd $\mathrm{M}$, et al. The serostatus approach to fighting the HIV epidemic prevention strategies for infected individuals. Am J Public Health. 2001; 91: 101924.

7. CDC. Syphilis. Atlanta: U.S. Department of Health and Human Services; 2008. [cited 2008 Dec 2]. Available from: http://www.cdc.gov/std/ syphilis/STDFact-Syphilis.htm.

8. CDC. Trichomoniasis. Atlanta: U.S. Department of Health and Human Services; 2007. [cited 2010 Mar 31]. Available from: http://www.cdc.gov/std/ trichomonas/STDFact Trichomoniasis. htm. 